\title{
Antioxidant Activity Assessment of Calpurnia aurea Root Extract \\ Dula $\mathrm{DE}^{1^{*}}$ and Zelalem $\mathrm{A}^{2}$
}

${ }^{1}$ Department of Chemistry, Nekemte College of Teacher Education, Post Box No. 88, Nekemte, Ethiopia

${ }^{2}$ Department of Chemistry, College of Natural and Computational Sciences, Wollega University, Post Box No. 395, Nekemte, Ethiopia

"Corresponding author: Dula DE, Department of Chemistry, Nekemte College of Teacher Education, Post Box No. 88, Nekemte, Ethiopia, Tel: +251923443592; E-mail: ladukan064@gmail.com

Received: December 02, 2017; Accepted: December 15, 2017; Published: January 03, 2018

Copyright: (C) 2018 Dula DE, et al. This is an open-access article distributed under the terms of the Creative Commons Attribution License, which permits unrestricted use, distribution, and reproduction in any medium, provided the original author and source are credited.

\begin{abstract}
Objective

In Ethiopia, any part of Calpurnia aurea is used for the treatment of different ailments: to destroy lice and ticks, to relieve itches, syphilis, malaria, rabies, diabetes, hypertension, diarrhoea, leishmaniasis, trachoma, elephantiasis, fungal diseases, stomach-ache, bowel, bladder disorders and different swellings. However, despite its traditional usage as an agent, there is limited or no information regarding the antioxidant activity assay profile of the root part unlike other parts. Hence; the researcher interested to assess the in vitro antioxidant activities of the root extracts of Calpurnia aurea.

\section{Methods}

Calpurnia aurea root was collected from around Jimma Arjo highland, East Wollega, Western Ethiopia. The collected plant material was dried and powdered using electrical grinder and then macerated within four organic solvents: hexane (99\%), chloroform (99.9\%), ethanol (97\%) and methanol (99.8\%) according to their increasing polarity index for 72 hours with mechanical shaking within 4 hours interval in average and it was filtered through Whatman No.1 filter paper and the filtrate was dried using Rotary evaporator. The in-vitro antioxidant properties were assessed through DPPH (1,1-diphenyl-2-picrylhydrazyl) in ethanol solution both qualitatively and quantitatively.

\section{Results}

The ethanol extract of the root part of Calpurnia aurea has shown better antioxidant activity at $100 \mu \mathrm{g} / \mathrm{mL}$ (81.63\%) when compared to the standard reference (ascorbic acid, 86.88\%) and other extracts (chloroform, methanol, and n-hexane i.e., $71.72 \%, 36.40 \%$ and $26.14 \%$, respectively) at the same concentration. Hexane root extract showed very weak or almost negligible activity.

\section{Conclusion}

It is evident from this study that highest the root part of the plant species has shown antioxidant potential which could be highly correlated with presence of flavonoids, tannins and phenolic compounds in general. Therefore, the root extract of Calpurnia aurea can be quantified for application in pharmaceutical industry.
\end{abstract}

Keywords: Absorbance; Antioxidant; DPPH; Calpurnia aurea; In vitro; In vivo; \% of Inhibition; Qualitative analysis; Quantitative analysis; Spectrophotometric method; TLC method

\section{Introduction}

Now-a-days world moving faster and every technology and service came in a nutshell of single word 'globalization' but this fast moving world brings very unhealthy and unhygienic lifestyle of fast food, 10-12 working hours, a diet which is lack of nutrients. Ultimately this all results in the increased oxidative stress in normal routine life of a human being. The oxidative stress causes various physiological and psychological disorders some common examples are atherosclerosis, heart disease, ageing, diabetes mellitus, immunosuppression, nervous disorders and others. To regulate the disorder, the helping hand came out in the form of synthetic antioxidant and various food supplements containing antioxidant, but these synthetic antioxidant capsules and dietary supplements are found to be less effective in various cases. In response to satisfy the thrust of antioxidants, many more medicinal plants were found which contain natural antioxidants that have shown beneficial therapeutic potentials. Several studies have demonstrated that plant(s) produce potent antioxidants. The majority of the antioxidant activity is due to the flavones, isoflavones, flavonoids, anthocyanin, catechins, isocatechins, phenolic compounds and tannins [1].

The term 'antioxidant' refers to the activity of numerous vitamins, minerals, and other phytochemicals to protect against the damage 
caused by reactive oxygen species (ROS). By their ability to react with and damage many structures in the body, ROS are involved in various physiological processes and diseases such as ageing, cancer, diabetes and atherosclerosis etc. [2].

Clinical trials and epidemiological studies have established an inverse correlation between the intake of fruits and vegetables and the occurrence of diseases such as inflammation, cardiovascular disease, cancer, and aging-related disorders. Dietary antioxidants, including polyphenolic compounds, vitamins $\mathrm{E}$ and $\mathrm{C}$, and carotenoids, are believed to be the effective nutrients in the prevention of these oxidative stress related diseases. Antioxidants have thus become a topic of increasing interest recently. A literature search revealed that the number of publications on antioxidants and oxidative stress has nearly quadrupled in the past decade (1684 in 2003; 6510 in 2013). It is of great interest to the general public, medical and nutritional experts, chemists and health and food science researchers to know the antioxidant capacity and constituents in the foods we consume and other natural products [3].

Calpurnia aurea is a genus of Flowering Plants within the family of fabaceae. The genus comprises shrubs or small trees in or along the margin of forests in many parts of Ethiopia and widely distributed in Africa from Cape Province to Eritrea and which also occurs in Southern India [4]. Literature survey brings to light that, all parts of the plant species has been used for different human and animal disease [5]. In native countries like Ethiopia, traditionally, the leave and powdered roots of Calpurnia aurea is used for the treatment of syphilis, malaria, rabies, diabetes, lung $\mathrm{TB}$, hypertension, diarrhoea, leishmaniasis, trachoma, elephantiasis, fungal diseases, different swellings, stomach-ache, abscesses, bowel, bladder disorders, to destroy maggots, to destroy lice, to relieve itches, used as a fish-poison or as a cure for dysentery, exhibit activity against amoebiasis and giardiasis, cough and snake bite [6]. Plant products have been part of phytomedicines since time immemorial. These can be derived from any part of the plant like stem bark, leaves, flowers, seeds and root i.e., any part of the plant may contain active components. Knowledge of the chemical constituents of plants is desirable because such information will be of value for the synthesis of complex chemical substances [7].

Thus, here in this study, qualitative and quantitative antioxidant activities analysis of the root extracts of Calpurnia aurea were assessed by using Spectrophotometric and Thin Layer Chromatography (TLC) methods. I hope that the findings from this work may add to the overall value of the medicinal potential of the plant species.

\section{Materials and Methods}

The plant sample of the study was collected from around Jimma Arjo highland (East Wollega Zone, about $50 \mathrm{~km}$ away from Nekemte town to the south-west direction, Western Ethiopia) at the end of June 2016 and the identity of the plant was confirmed by botanical scholars from Wollega University Biological Science Department with the reference of National Museums of Ethiopia Herbarium. Appropriate voucher specimen designated was deposited at the School of Botanical science, Wollega University.

\section{Extraction}

The whole root part was washed in tap water and cut in to small bits to facilitate drying. After weighing the wet sample, it was hot-air ovendried below $55^{\circ} \mathrm{C}$ for $14 \mathrm{~h}$ until it came to constant weight. Then the preliminary quantitative moisture difference was calculated and the complete dry sample was powdered to suitable size first the root bark and the inner part separately, and then homogenized. The powdered sample was stored in clean glassware container. The prepared powder weighed (380 g) and then macerated by using four organic solvents hexane (99\%), chloroform (99.9\%), ethanol (97\%) and methanol (99.8\%) according to their increasing polarity index for 72 hours with mechanical shaking within 4 hours interval in average and it was filtered through Whatman No.1 filter paper and the filtrate was dried using Rotary evaporator.

\section{In vitro antioxidant activity assay}

The quantitative and qualitative analysis of in vitro antioxidant activity was done to assess the antioxidant potential of the Calpurnia aurea root extract by using DPPH scavenging assay method and ethanol as solvent selectively. The in vitro antioxidant of Calpurnia aurea root extract was measured using DPPH according to Choi et al. [8].

\section{Using spectrophotometric method}

The DPPH radical-scavenging activity of the test extracts was examined according to the procedures as follows: $1 \mathrm{~mL}$ of different concentrations, $10 \mu \mathrm{g} / \mathrm{mL}, 20 \mu \mathrm{g} / \mathrm{mL}, 40 \mu \mathrm{g} / \mathrm{mL}, 60 \mu \mathrm{g} / \mathrm{mL}, 80 \mu \mathrm{g} / \mathrm{mL}$, and $100 \mu \mathrm{g} / \mathrm{mL}$, of each extract and standard were taken in different test tubes at an equal volume and to these solutions, $3 \mathrm{~mL}$ of ethanol solution of DPPH $(0.1 \mathrm{mM})$ was added and the mixture was allowed to react at room temperature in the dark within 30 minutes of incubation. Vitamin C (ascorbic acid) was used as standard controls. Three replicates were made for each test sample. After 30 minutes, the absorbance (A) was measured at $517 \mathrm{~nm}$ and converted into the percentage antioxidant activity and interpreted in terms of $\%$ scavenged. $\mathrm{IC}_{50}$ value (concentration of sample where absorbance of DPPH decreases $50 \%$ with respect to absorbance of the control) of extracts were determined. The higher the antioxidant activity, the lower $\mathrm{IC}_{50}$ value [7].

\section{Using Thin Layer Chromatography (TLC) method}

The in-vitro antioxidant activity of Calpurnia aurea root extract was measured using DPPH according to Choi et al. [8]. The experiment was conducted in two ways: solvent fractionation and reagent spraying.

Thin-layer chromatography was carried out on all the fractions using TLC pre-coated plates (silica gel $60 \mathrm{~F}_{254}$ ) by using one way ascending technique. The plates were activated in an oven at $100^{\circ} \mathrm{C}$ for $20 \mathrm{~min}$ to drive off the water molecule that bond to the polar site on the plate. And then the plates were cut with surgical blade and marked with pencil about $1 \mathrm{~cm}$ from the bottom of the plate. The extracts to be analysed were diluted with respective solvents (n-hexane, chloroform, ethanol and methanol) and then spotted with help of capillary tube just $1 \mathrm{~cm}$ above its bottom and allowed to dry. The plates were developed in a chromatographic tank or chamber using the different solvent systems. Solvents were analysed as its order of increasing polarity. After several trials, the best solvent system was selected which showed good positive result upon color detection. For each test, the plates were dried and visualized under normal day light after spraying with DPPH in ethanol solution reagent and approved by using UV lamp [9].

According to Choi et al., [8] the developed bands were sprayed with spraying reagents by using $2.5 \mu \mathrm{L}$ micropipette of the prepared sample solution as stated above and observed in daylight and by using UV 
lamp after being dried. For application of simple diffusion of $0.1 \mathrm{mM}$ DPPH ethanol solutions on the dried plate carrying sample spot, in vitro antioxidant properties of these various concentrations of four different solvents extract of Calpurnia aurea root part $(100,200,300$ $\mathrm{mg} / 100 \mathrm{~mL}$ for each) were tested. The spot exhibiting radical scavenging activity of the antioxidant against the color of the background was observed and related in both cases. The experiment was performed in triplet.

\section{Results}

\section{In vitro antioxidant activity by using spectrophotometric method}

Ethanol extract of the root sample of Calpurnia aurea has shown better antioxidant activity when compared to the standard reference (ascorbic acid, which was 86.88\%) and other extracts tested. The ethanol root extract has shown $81.63 \%$ of antioxidant activity at 100 $\mu \mathrm{g} / \mathrm{mL}$ as compared to others (chloroform, methanol, and $\mathrm{n}$-hexane i.e., $71.72 \%, 36.40 \%$ and $26.14 \%$, respectively) solvents root extract. Hexane root extract showed very weak or negligible activity. All the antioxidant activities in different concentrations are shown as a bar and line graphs in Figures 1 and 2 respectively.

From the antioxidant activity, the $\mathrm{IC}_{50}$ values of test and standard samples were determined. The standard i.e., ascorbic acid shows 16.33 $\mu \mathrm{g} / \mathrm{mL} \mathrm{IC}_{50}$ value. In the various extracts the ethanol root showed $23.60 \mathrm{IC}_{50}$ value which is less in all extracts. After the ethanol $\mathrm{IC}_{50}$ value, chloroform extract show relatively significant $\mathrm{IC}_{50}$ value which was 48.46 . The other two extracts i.e., hexane and methanol showed very high $\mathrm{IC}_{50}$ value which was 198.14 and $141.42 \mu \mathrm{g} / \mathrm{mL}$. The experimental analysis of all extracts showed that for the entire examined root extracts rank order in terms of \% antioxidant activity efficiency was always: ethanol $>$ chloroform $>$ Methanol $>$ hexane. But it was also observed that all the sample extracts have lesser activity than that of standard ascorbic acid which was found $\mathrm{IC}_{50}$ value $16.33 \mu \mathrm{g} / \mathrm{mL}$ in the ethanol solution shown by Figure 3 .

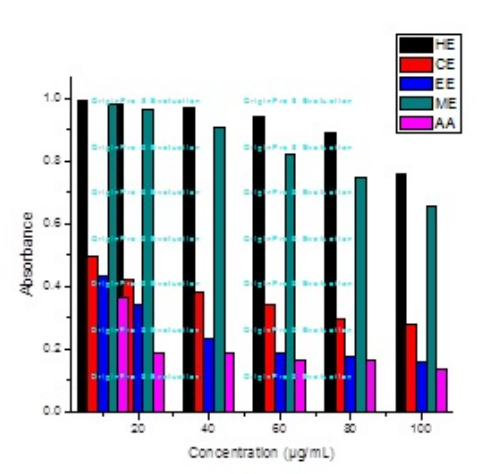

Figure 1: Bar graph plot of absorbance versus concentration of standard and different fractions of Calpurnia aurea root extract (HE-Hexane extract; CE-Chloroform extract; EE-Ethanol extract; ME-Methanol extract).

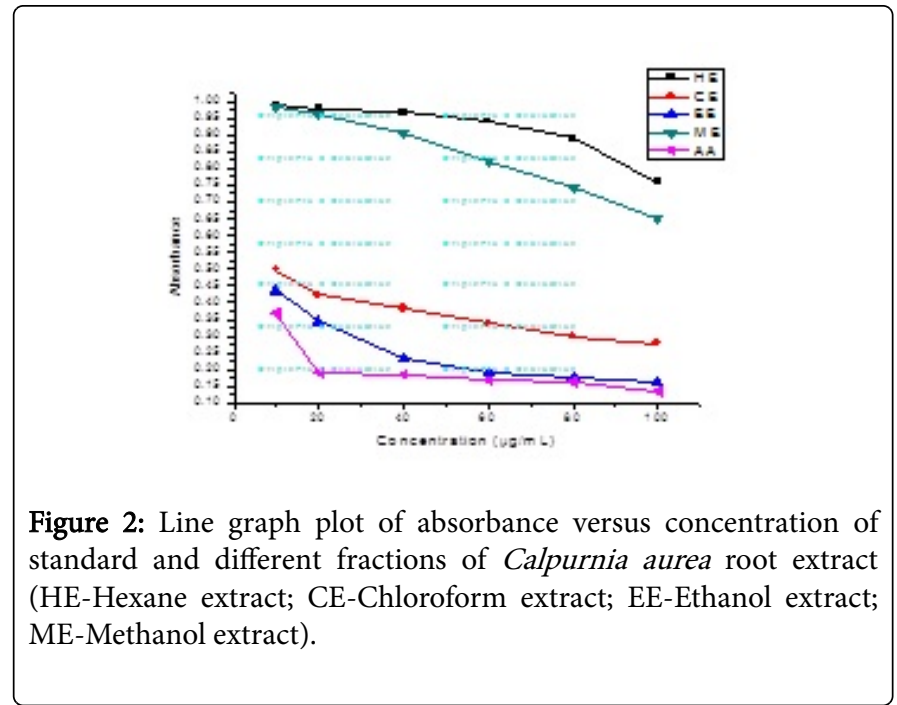

The percentage inhibition in Calpurnia aurea root extract and standard Ascorbic acid Vs. concentration showed that the antioxidant activities of $97 \%$ ethanol extract of Calpurnia aurea root and the standard Ascorbic acid was found to be positively correlated with the $\%$ inhibition as determined from their corresponding regression curves. This comparison suggested that the solvent extracts are relatively potential antioxidant agents and compatible with the commercial antioxidant agent. However, that of methanol is not correlated. Table 1 below shows for all in vitro antioxidant activity assay results by using spectrophotometric method.

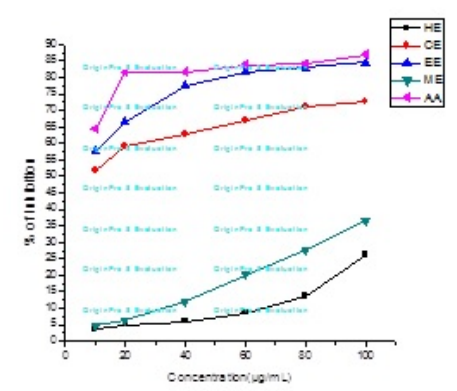

Figure 3: Plot of \% DPPH radical scavenging activity versus concentration of standard and different fractions of Calpurnia aurea root extract (HE-Hexane extract; CE-Chloroform extract; EEEthanol extract; ME-Methanol extract).

\section{In vitro antioxidant activity by using TLC method}

The antioxidant capacities of the root of Calpurnia aurea plant extracts as measured by the DPPH method qualitatively are presented in Figure 4 below.

The plant extracts which were run under the EMW (40:5.4:5) solvent system showed similar activity with the above solvent systems shown in Figure 4. In the chromatograms sprayed by DPPH ethanol solution, ethanol and chloroform showing stronger antioxidant activity in all solvent systems used next to which methanol extract comes where as there is no or almost negligible activity indicated by hexane 
Citation: Dula DE, Zelalem A (2018) Antioxidant Activity Assessment of Calpurnia aurea Root Extract. Nat Prod Chem Res 6: 307. doi:

Page 4 of 6

extract. This is related to the science of polarity of the components of the compounds present in the extractants. On the other hand, the direct diffusion that was applied based on three different respective concentrations of the sample extracts showed significant results.

\begin{tabular}{|c|c|c|c|c|c|c|c|c|c|c|c|c|c|c|c|}
\hline \multirow{2}{*}{$\begin{array}{l}\text { Conc. } \\
(\mathrm{mg} / \mathrm{mL})\end{array}$} & \multicolumn{3}{|c|}{ Hexane Extract } & \multicolumn{3}{|c|}{ Chloroform Extract } & \multicolumn{3}{|c|}{ Ethanol Extract } & \multicolumn{3}{|c|}{ Methanol Extract } & \multicolumn{3}{|c|}{ Ascorbic Acid } \\
\hline & A & $\% 1$ & $\begin{array}{l}\mathrm{EC}_{50} \\
(\mathrm{mg} / \mathrm{mL})\end{array}$ & A & $\% 1$ & $\begin{array}{l}\mathrm{EC}_{50} \\
(\mathrm{mg} / \mathrm{mL})\end{array}$ & A & $\% 1$ & $\begin{array}{l}\mathrm{EC}_{50} \\
(\mathrm{mg} / \mathrm{mL})\end{array}$ & A & $\% 1$ & $\begin{array}{l}\mathrm{EC}_{50} \\
(\mathrm{mg} / \mathrm{mL})\end{array}$ & A & $\% 1$ & $\begin{array}{l}\mathrm{EC}_{50} \\
(\mathrm{mg} / \mathrm{mL})\end{array}$ \\
\hline 10 & 0.99 & 3.79 & \multirow[t]{6}{*}{198.14} & 0.496 & 32.36 & \multirow[t]{6}{*}{48.46} & 0.435 & 41.89 & \multirow[t]{6}{*}{23.6} & 0.981 & 4.66 & \multirow[t]{6}{*}{141.42} & 0.367 & 42.76 & \multirow{6}{*}{16.33} \\
\hline 20 & 0.978 & 5.64 & & 0.422 & 37.51 & & 0.343 & 48.3 & & 0.965 & 6.22 & & 0.19 & 48.69 & \\
\hline 40 & 0.967 & 8.45 & & 0.382 & 43.44 & & 0.232 & 58.31 & & 0.906 & 11.95 & & 0.187 & 67.74 & \\
\hline 60 & 0.94 & 14.67 & & 0.339 & 56.75 & & 0.189 & 69.68 & & 0.822 & 20.12 & & 0.167 & 78.72 & \\
\hline 80 & 0.889 & 20.8 & & 0.297 & 67.06 & & 0.175 & 74.25 & & 0.745 & 27.6 & & 0.164 & 84.06 & \\
\hline 100 & 0.76 & 26.14 & & 0.279 & 71.72 & & 0.16 & 81.63 & & 0.654 & 36.44 & & 0.135 & 86.88 & \\
\hline
\end{tabular}

Table 1: Absorbance, \%inhibition and EC50 by DPPH for Samples of Calpurnia aurea Root Extract of Four Different Solvents and Standard Reference (Ascorbic Acid).

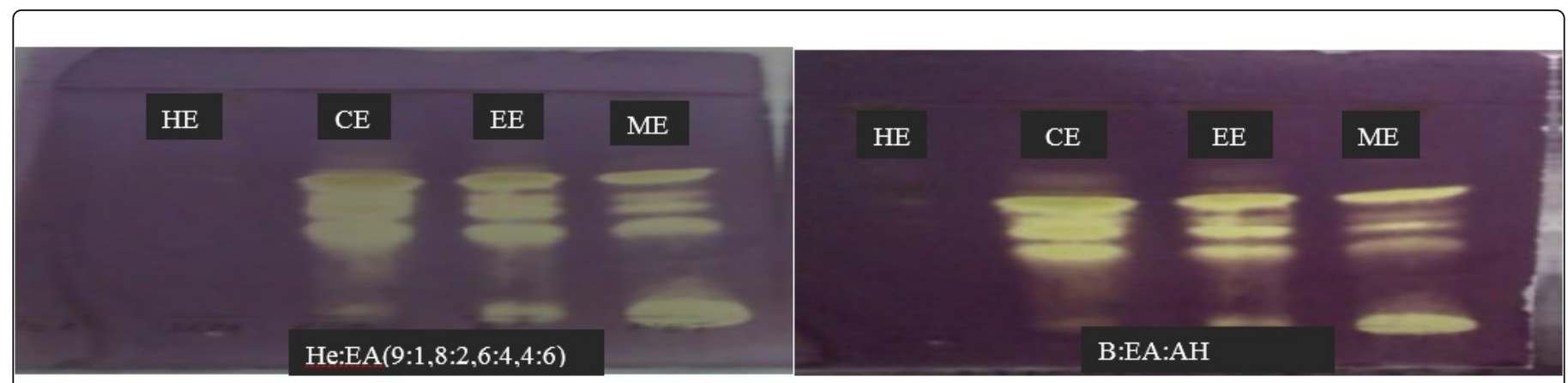

Figure 4: Chromatograms of antioxidant activity sprayed with DPPH in different solvent system: HE-Hexane extract; CE-Chloroform extract; EE-Ethanol extract; ME-Methanol extract; He-Hexane; EA-Ethyl acetate; B-Benzene; AH-Ammonium hydroxide.

The Thin-Layer Chromatography (TLC) plate immersed in DPPH solution loaded with $300 \mathrm{mg} / 100 \mathrm{~mL}$ of the root extract of ethanol solvent showed highest reducing ability. To some extent, similar result but less strong were obtained from chloroform and methanol extracts (Figure 5).

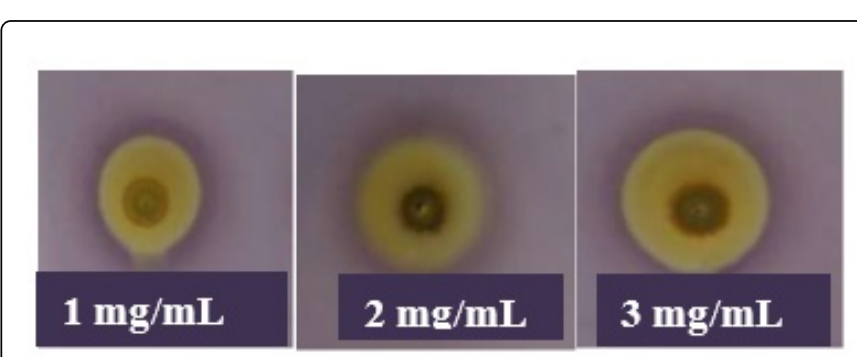

Figure 5: In vitro anti-oxidant properties of various concentration of $97 \%$ ethanol extract of Calpurnia aurea root extract $(100,200$, $300 \mathrm{mg} / 100 \mathrm{~mL}$ ) from left to the right, respectively.

\section{Discussion}

Gorinstein et al. [10] has reported that the high antioxidant activity of plant extracts were due to the presence of high phenolic, tannins and flavonoids compounds which are polar compounds in the hydroalcoholic or alcoholic extracts. In addition, [11] Guha has conducted a study that showed that the polar solvent extract (lower molecular weight alcohols and aqueous) possessed a higher antioxidant activity when compared to non- polar (e.g., hexane) or low polar (e.g., chloroform) extracts over 56 different type of plants. There have been also many studies reported that the other parts of the plant species showed significant DPPH radical scavenging activity and possessed high antioxidant activity. The stems and leaves of Calpurnia aurea showed significant activity where the leaves showing higher potential when evaluated by using DPPH and FRAP standard methods [12]. The extract showed significant activities in all antioxidant assays compared to the reference antioxidant ascorbic acid in a dose dependent manner [13,14].

Here in the present study, ethanol extract of the root part of Calpurnia aurea has shown better antioxidant activity at $100 \mu \mathrm{g} / \mathrm{mL}$ when compared to the standard reference (ascorbic acid, which was $86.88 \%$ ) and other extracts tested. The ethanol root extract has shown $81.63 \%$ of antioxidant activity as compared to others (chloroform, methanol, and n-hexane i.e., $71.72 \%, 36.40 \%$ and $26.14 \%$, respectively) 
Page 5 of 6

at the same concentration. Hexane root extract showed very weak or negligible activity.

The result obtained from methanol extract seemed odd when seen in the science of polarity perspective and results shown by different authors on other different parts of Calpurnia aurea or other plant species. This can be explained based on the science of chemical kinetics and working nature of DPPH chemical.

Sanchez-Moreno, et al. classified the kinetic behaviour of the antioxidant compound as follows: $<5 \mathrm{~min}$ (rapid), 5-30 $\mathrm{min}$ (intermediate), and $>30 \mathrm{~min}$ (slow). A representative kinetic curve of a DPPH assay is shown in Figure 6.

Although the DPPH assay is widely applicable, there are some disadvantages that limit its usage. Besides the mechanistic difference from the HAT reaction that normally occurs between antioxidants and peroxyl radicals, DPPH is long-lived nitrogen radical, which bears no similarity to the highly reactive and transient peroxyl radicals involved in lipid peroxidation. Many antioxidants that react quickly with peroxyl radicals may react slowly or may even be inert to DPPH. This is evident from the $\mathrm{T}_{\mathrm{EC} 50}$ values ranging from $1.15 \mathrm{~min}$ (ascorbic acid) to $103 \mathrm{~min}$ (rutin). Consequently, the antioxidant capacity is not properly rated. The reaction kinetics between DPPH and antioxidants are not linear to DPPH concentrations (Figure 6).
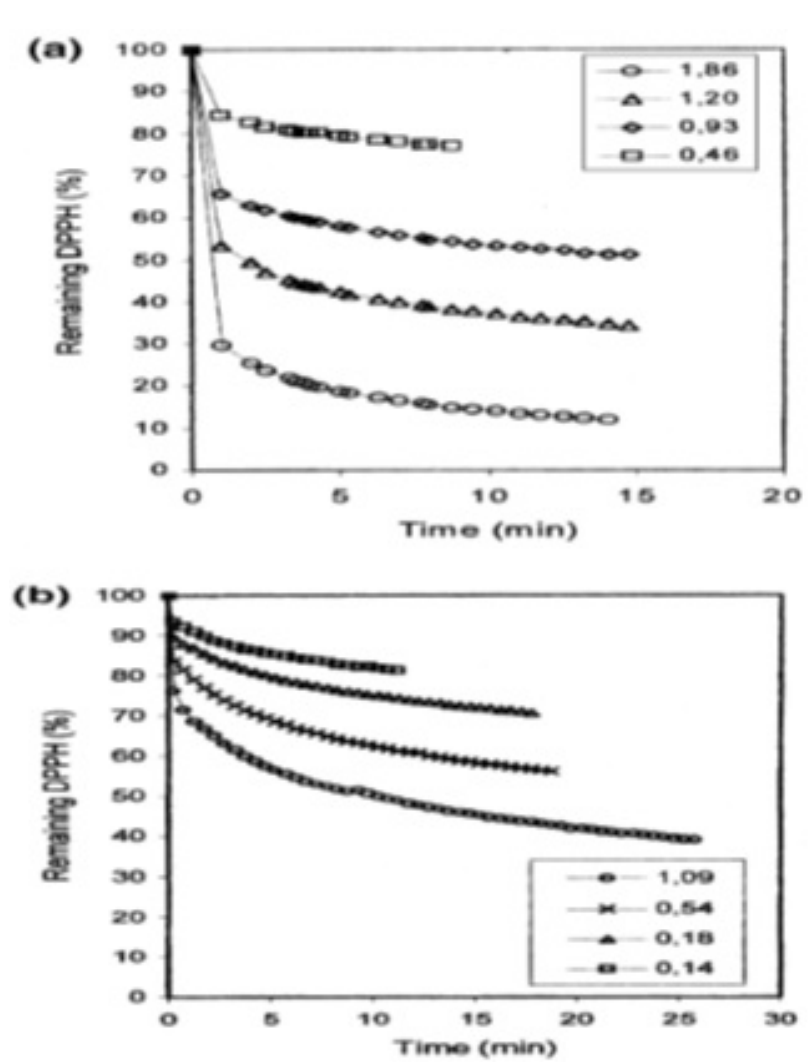

Figure 6: DPPH bleaching kinetics in the presence of different concentrations of $\alpha$-carotene (a) and $\beta$-xanthophylls (b).

\section{Conclusion}

According to this study, the methanol extract of Calpurnia aurea root gave the highest percentage yield of extraction and followed by ethanol in contrast to $n$-hexane extract indicating that the root extract contained more polar compounds than non-polar compounds.

The DPPH assay showed that ethanol extract gave the highest antioxidant activity even at low concentration and chloroform extract also can be a potential antioxidant agent as it was able to scavenge high percentages of free radical. The qualitative thin layer chromatography also revealed that the Calpurnia aurea root extract contained several polar and slightly non polar compounds as they did show higher positive results for all solvents extract (except hexane extract) showing yellowish colour spots on purple background upon spraying and diffusing DPPH methanol solution on developed chromatogram. The ethanol extract showed significant antioxidant activity in comparative to standard ascorbic acid means that in future this plant may found the main source for drug supplement as an antioxidant since the antioxidant activity has potential in the treatment of cancer, cardiovascular disease, neural disorders, Alzheimer's disease, mild cognitive impairment, Parkinson's disease, alcohol induced liver disease, ulcerative colitis, aging and atherosclerosis. The exploitation of these pharmacological properties involves further investigation of these active ingredients by implementation techniques of extraction, purification, separation, crystallization, characterisation and identification.

\section{References}

1. Killedar S, More H, Shah G, Gaikwad S (2013) Phytochemical Screening and In vitro Antioxidantactivity of Memecylon Umbellatum Root Extracts. World J Pharm Pharmaceut Sci 2: 5988-5996.

2. Priyanka P, Junaid N, Gagandeep C, Kalia AN (2011) In vitro antioxidant potential of Jasminum mesnyi Hance (Leaves) extracts. RJPBCS 2: 351.

3. Dejian H, Boxin OU, Ronald LP (2005) The Chemistry behind Antioxidant Capacity Assays. J Agric Food Chem 53: 1841-1856.

4. Korir E, Joyce JK, Neil RC, Nivan M, Neil AK (2014) Isoflavones from Calpurnia Aurea Subsp. Aurea and Their Anticancer Activity. Afr J Tradit Complement Altern Med 11: 33-37.

5. Gemechu A, Mirutse G, Adane W, Gobena A (2013) In vitro Antimycobacterial activity of selected medicinal plants against Mycobacterium tuberculosis and Mycobacterium bovis Strains. BMC Complem Alternat Med 13: 291.

6. Tadeg H (2004) Phytopharmaceutical Studies of Some Selected Medicinal Plants Locally Used in the Treatment of Skin Disorders.

7. Gnanasekaran N, Haile N, Umeta M, Seifu D (2015) Phytochemical Screening and Assessment of In Vitro Antioxidant Activities of Calpurnia Aurea Seeds and Leaves. IJPPR Huma 2: 1-12.

8. Choi CW, Kim SC, Hwang SS, Choi BK, Ahn HJ, et al. (2002) Antioxidant activity and free radical scavenging capacity between Korean medicinal plants and flavonoids by assay-guided comparison. Plant Sci J 163: 1161-1168.

9. Alebiosu CO, Yusuf AJ (2015) Phytochemical Screening, Thin-layer Chromatographic Studies and UV Analysis of Extracts of Citrullus lanatus. J Pharm Chem Biol Sci 3: 214-220.

10. Gorinstein S, Oscar J, Vargas M, Jaramillo NO, Salas IA, et al. (2007) The total polyphenols and the antioxidant potentials of some selected cereals and pseudocereals. European Food Res Technol 225: 321-328.

11. Guha G, Rajkumar V, Mathew L, Kumar RA (2011) The antioxidant and DNA protection potential of Indian tribal medicinal plants. Turkish J Bio 35: 233-242.

12. Adedapo AA, Jimoh FO, Koduru S, Afolayan AJ, Masika PJ (2008) Antibacterial and antioxidant properties of the methanol extracts of the 
Citation: Dula DE, Zelalem A (2018) Antioxidant Activity Assessment of Calpurnia aurea Root Extract. Nat Prod Chem Res 6: 307. doi: 10.4172/2329-6836.1000307

Page 6 of 6

leaves and stems of Calpurnia aurea. BMC Complement Altern Med 8: 53-61.

13. Mulata N, Seifu D, Umeta M, Wendwesson E, Natesan G (2015)

Protective Effects of Calpurnia aurea Seed Extract on HAART Hepatotoxicity. EJMP 9: 1-12.
14. Sharma M, Joshi S (2011) Comparison of anti-oxidant activity of Andrographis paniculata and Tinospora cordifolia leaves. J Current Chem Pharmaceut Sci 1: 1-8. 